\title{
Do GPAE à UPP: uma proposta de interpretação das percepções de moradores de favelas acerca dos projetos de policiamento comunitário ou de proximidade
}

\author{
Marcus Cardoso \\ INCT/InEAC e PPGEF/UNIFAP \\ marcusacardoso@gmail.com
}

\begin{abstract}
Resumo Neste artigo exploram-se os fatores envolvidos no processo de avaliação da UPP e do GPAE pelos moradores de duas favelas cariocas. Um empreendimento dessa natureza só pode ser levado adiante quando dedicamos cuidadosa atenção àquilo que é dito por nossos interlocutores. Proceder dessa maneira permite-nos identificar em suas falas eventuais recorrências que remetem às estruturas de significado com que interpretam suas experiências. Uma compreensão adequada da percepção dos moradores das favelas monitoradas acerca do GPAE e da UPP só é possível se atentarmos para a importância que eles atribuem às práticas que nomeiam como "respeitosas" ou "desrespeitosas" ao apreciarem a ação dos policiais que atuam nessas favelas. Com essa visão, procura-se explorar aqui o potencial analítico das aproximações entre as categorias nativas "respeito" e "desrespeito" e as categorias analíticas "consideração" e "insulto moral".
\end{abstract}

Palavras-chave: Policiamento comunitário, favelas, reconhecimento, insulto moral, respeito.

\section{Introdução}

Z $\mathrm{m}$ 2013, iniciou-se um questionamento mais agudo do projeto batizado de Unidade de Polícia Pacificadora (UPP), de iniciativa da Secretaria Estadual de Segurança Pública do Rio de Janeiro. Após um longo período em que as opiniões negativas sobre as UPP não tinham espaço na esfera pública, mídias alternativas e moradores de favelas conseguiram dar visibilidade a suas críticas denunciando abusos e crimes cometidos por policiais. O evento que marcou esta virada foi o desaparecimento e assassinato do morador da favela da Rocinha conhecido por Amarildo, assassinado por agentes da UPP numa operação policial durante a primeira quinzena de julho de 2013. Os policiais envolvidos foram flagrados conduzindo Amarildo para dentro de um posto da UPP e, posteriormente, acompanhando-o para um local desconhecido. Depois de grande repercussão do crime nas redes sociais e nos jornais, eles tiveram suas prisões preventivas decretadas. Na mesma época, após investigações preliminares, criou-se a suspeita de que a UPP da Rocinha era sistematicamente utilizada como centro de tortura para a 
obtenção de informações sobre possíveis esconderijos de armas e drogas dentro da favela. O desencadear dos acontecimentos colocou sob suspeição o comportamento de todos os policiais ligados às UPP no Rio de Janeiro.

O chamado "caso Amarildo" parece ter sido o estopim para que as críticas elaboradas por acadêmicos e moradores de favelas conquistassem espaço na esfera pública. Ganharam destaque os dados disponibilizados pelo Instituto de Segurança Pública que apontavam o aumento do número absoluto de desaparecimento de pessoas onde haviam sido instaladas UPP entre os anos de 2007 e 2012..$^{1}$ Os números lançaram dúvidas sobre os métodos utilizados para a manutenção da "paz" nas localidades onde elas atuavam, dando argumentos para os críticos do projeto, que interpretavam os dados do Instituto de Segurança Pública como indícios de que o ocorrido com Amarildo não era um caso isolado.

Este é um cenário muito distinto do observado durante os primeiros anos de atuação das UPP, sobretudo se recuarmos até o mês de novembro de 2010, quando membros do grupo que controlava a venda de drogas ilícitas na favela carioca Vila Cruzeiro abrigaram-se no Complexo do Alemão, fugindo de uma operação policial. Reforçando dicotomias equivocadas que aludiam a uma batalha do bem contra o mal, revistas semanais e jornais referiam-se ao acontecimento como "O dia em que o Brasil começou a vencer o crime" 2 e "O dia em que a esperança venceu o terror". ${ }^{3}$ Nesse momento, as reflexões sobre os problemas que assolavam, e ainda assolam, as instituições policiais foram desconsideradas.

A UPP não foi a primeira experiência baseada nos princípios do policiamento de proximidade ou comunitário no Rio de Janeiro. Antes dela, outro projeto que alcançou grande repercussão foi o Grupamento de Policiamento em Áreas Especiais (GPAE). Como pesquisador, acompanhei, em um universo temporal que se iniciou em 2001 e se estendeu até 2007, a atuação do GPAE nas favelas cariocas do Cantagalo e do Pavão-Pavãozinho, situadas na zona sul da cidade do Rio de Janeiro. Posteriormente, nos anos de 2013 e 2014, retornei ao campo, interessado no impacto que a UPP, instalada em 2009, causara nas localidades. É interessante notar que as duas inciativas passaram por processos semelhantes, podendo ser sintetizadas da seguinte maneira: durante o momento das implantações, ambas tiveram um desempenho considerado satisfatório e gozavam do apoio de parte significativa dos moradores das duas favelas com quem mantive relações no campo. Depois, gradativamente, passaram a ser alvo de críticas mais sistemáticas e declarações de descontentamento.

Ao tomar essas experiências de pesquisa como referência, neste artigo, estou interessado em explorar os fatores envolvidos no processo da avaliação feita por meus interlocutores sobre esses dois projetos implementados pela Secretaria de Segurança Pública do Rio de Janeiro. Um empreendimento dessa natureza só pode ser levado adiante quando se dedica especial e cuidadosa atenção àquilo que é dito pelos interlocutores. Procedendo dessa maneira, conseguimos identificar em suas falas eventuais recorrências que remetem às estruturas de significado de que se utilizam para interpretar suas experiências. Esta abordagem propicia superar o risco de tratar as falas dos interlocutores de forma abstrata, empregando formulações e conceitos que, aplicados a toda e qualquer situação, desconsideram os contextos particulares onde estas falas ocorrem e o conteúdo que expressam.

Sustento que uma compreensão adequada da percepção dos moradores das duas favelas acerca do GPAE, e também da UPP, é possível apenas se atentarmos para a importância que eles atribuem às práticas que nomeiam como "respeitosas" ou "desrespeitosas" ao apreciarem a ação dos policiais que atuam nessas favelas. Com essa visão, procuro explorar o potencial analítico das aproximações entre as categorias nativas "respeito" e "desrespeito" e as categorias analíticas "consideração" e "insulto moral" (Cardoso de Oliveira, 2002, 2011a, 2011b, 2013). Faço isso inicialmente utilizando como base para a discussão o material referente ao período em que acompanhei a atuação do GPAE nas duas favelas. Acredito que ele permite jogar luz sobre a experiência local com a UPP. Em seguida, trago alguns dados especificamente relacionados com o período de acompanhamento da atuação da UPP a fim de comparar esses materiais, demonstrando a pertinência de observar essas experiências a partir da chave analítica que proponho.

\section{O GPAE nas duas favelas}

O Grupamento foi criado na segunda metade do ano de 2000, durante o mandato de Anthony Garotinho, governador do estado do Rio de Janeiro. Foi idealizado como uma unidade especializada no patrulhamento e na ocupação das favelas cariocas

1. Dados disponíveis em Uol Notícias, 3 ago. 2013.

2. A matéria de capa da revista Veja, edição número 2.193, de primeiro de dezembro do ano de 2010, trazia este título.

3. Título da matéria veiculada no site da revista Veja do dia 28 de novembro de 2010. 
e inspirado nos princípios operacionais daquilo que se convencionou chamar de "policiamento comunitário" ou "policiamento de proximidade". As primeiras localidades a receber o GPAE foram o Pavão-Pavãozinho e o Cantagalo, e, posteriormente, mais unidades foram instaladas em outras favelas do estado (Albernaz; Caruso; Patrício, 2006). Como demonstra a literatura, a premissa da "coprodução de segurança” geralmente é o denominador comum dos empreendimentos classificados na rubrica da segurança. Isso indica que, para diminuir a sensação de insegurança e potencializar a qualidade dos serviços prestados pelos policiais, é necessário o envolvimento ativo da sociedade civil no processo de produção de segurança e prevenção ao crime (Skolnick; Bayley, 2002; Rosenbaum, 2002; Núcleo de Estudos da Violência da Universidade de São Paulo, 2009). Na esfera operacional, entende-se que o policiamento deve priorizar o atendimento de situações não emergenciais, procurando resolver problemas ainda nos seus estágios iniciais (Skolnick; Bayley, 2002; Rosenbaum, 2002).

O GPAE, ao menos no âmbito discursivo, assumia esses pressupostos como modelo para sua organização e atuação cotidiana. Anunciava-se que seus agentes operariam de modo a criar condições que favorecessem estratégias de prevenção ao crime, sempre em diálogo com os moradores das favelas onde atuassem. Para isto, o Grupamento permaneceria 24 horas nas localidades e prestaria serviço de polícia ostensiva, inibindo a ocorrência de situações que colocassem vidas em risco e que representassem uma ameaça aos direitos civis dos moradores (Blanco, 2003, p. 103).

Nas palavras do comandante Antônio Blanco, entre as funções do Grupamento, se destacariam procedimentos que promovessem a:

1) prevenção do crime, com ênfase nas situações de risco pessoal e social que afligem crianças e adolescentes;

2) redução do medo, por meio do esforço contínuo (regular e interativo) empreendido pela ação do policiamento ostensivo a fim de neutralizar o domínio territorial armado, exteriorizado pela dinâmica do tráfico de drogas;

3) repressão qualificada do tráfico e do uso de drogas nas hipóteses de flagrante delito ou em cumprimento de mandato judicial;

4) prevenção e repressão de eventual conduta irregular praticada pelo policial, nas hipóteses de cometimento de transgressão disciplinar e de crime (Blanco, 2003, p. 108-109).
É importante sublinhar que a escolha das favelas como palco de atuação de projetos dessa natureza não deve ser compreendida como fruto do acaso. Historicamente estas localidades sempre foram representadas como local da pobreza, degeneração, marginalidade e violência (Perlman, 1977; Valladares, 2005). Tal estigma é reiterado na década de 1980 com a consolidação dos grupos organizados para a comercialização de drogas ilícitas, os quais passaram a se estruturar tomando as favelas como base de suas operações (Zaluar, 1985). Este fenômeno desencadeou o apelo das camadas médias do estado ao recrudescimento da ação policial nas favelas, inclusive como forma de conter o avanço contra os direitos humanos e de cidadania daqueles que viviam nas áreas dominadas pelo tráfico (Soares, 1996). O GPAE e a UPP, sobretudo discursivamente, surgiram, portanto, com a promessa de modificar esse cenário de abuso contra a população que reside em favelas, criando as condições para a garantia dos seus direitos civis. Em contrapartida, é necessário considerar que, procurando minimizar a sensação de medo das camadas médias das populações carioca e fluminense, eles podem representar uma tentativa de circunscrever determinadas modalidades de violência a certas áreas geográficas.

\section{O GPAE e os moradores das favelas monitoradas}

A partir de agora, passo a apresentar alguns procedimentos adotados pelos policiais do GPAE e sua repercussão sobre os meus interlocutores do Cantagalo e do Pavão-Pavãozinho. Retorno ao período que cobre o primeiro ano de atuação do policiamento nas duas favelas quando estava bem-encaminhada minha aproximação com Ruth, moradora do Pavão-Pavãozinho. Naquela época, ela já depositava certa confiança em mim, a ponto de falar, em particular, sobre o que pensava dos membros de tráfico e dos policiais. Àquela altura, ela ainda possuía sentimentos ambíguos em relação à presença de um posto de policiamento comunitário (PPC) em frente a sua casa. Como ela mesma disse certa vez, depois de tantos anos no Pavão-Pavãozinho presenciando crimes cometidos por policiais, vendo-os agredir e até executar não apenas desafetos dela como também pessoas que não pertenciam ao bando local, era difícil, de uma hora para outra, confiar que tudo mudara. Porém, quando menos esperava, bem diante da sua casa, policiais começaram a se fazer presentes ininterruptamente. E, apesar da desconfiança, ela admitia que as coisas haviam melhorado na favela. 
Melhorado por quê? Porque a presença do policiamento constrangeu o movimento, ${ }^{4}$ dizia ela. Sua experiência ensinara que os integrantes do movimento também eram perigosos. Assim como os policiais, eles também matavam, agrediam, humilhavam e desrespeitavam as pessoas de bem. ${ }^{5}$ Resumindo: ela desconfiava da polícia, mas estava satisfeita com as consequências de sua presença no Pavão-Pavãozinho. O detalhe ainda não mencionado é que o PPC instalado em frente à sua casa ocupou um ponto físico importante na dinâmica e organização do movimento. Aquele era justamente o local onde antes as drogas eram embaladas e onde ocorriam alguns acertos de conta. Ruth diz que havia perdido as contas de quantas vezes presenciara episódios ditos por ela como violentos.

À época, ela tinha 45 anos e morava com suas duas filhas, Maria e Clara, a primeira com 16, e a segunda com 22 anos. Não havia completado um ano que seu ex-marido saíra de casa para morar com outra mulher numa favela vizinha. Para Ruth, estar sem a companhia de um homem, sozinha com suas duas filhas, era um risco, um motivo a mais de preocupação. No seu entendimento, suas filhas poderiam ser vítimas dos assédios e abusos comumente praticados pelos membros do movimento, justamente por não haver uma figura masculina que as protegesse. Já para suas filhas, o problema real era o fato de o movimento não respeitar ninguém.

Seu Augusto, aposentado, viúvo e morador da favela Pavão-Pavãozinho, tinha opinião semelhante à de Ruth. Ele também desconfiava da polícia, mas estava satisfeito com as consequências da presença do GPAE:

A polícia é a polícia. Tem que desconfiar porque eles têm os vícios e essas coisas não mudam de uma vez. Mas, respondendo sua pergunta, eu acho que melhorou sim. Não é a maravilha que dizem na TV, mas é verdade que está melhor. Os tiroteios pararam... e tem essa coisa deles não subirem atirando.

Débora, outra interlocutora durante minha pesquisa de campo e moradora do Cantagalo, era mais explícita ao ressaltar como, em sua opinião, a chegada do Grupamento gerou um impacto positivo no cotidiano local. Nascida naquela favela e com 29 anos, nunca havia morado em outro lugar.

É claro que eu prefiro eles aqui. Você não tem ideia do que é morar em lugar que, em qualquer momento, você pode levar um tiro. Que se vê alguém apanhar até a morte ou que, quando você abre a porta de casa, ou está descendo para o trabalho, tem um corpo largado no chão. Nada, nada mesmo, garante que não sou eu ali, na vala. Essa coisa que dizem que morador de favela gosta do tráfico é mentira. A gente vive é com medo. Então, é claro, eu prefiro como está agora. (Grifo meu).

Para Débora, a referida transformação não se restringia à inibição das práticas abusivas adotadas pelo tráfico. Ela entendia que havia ocorrido, também, uma modificação na forma como os policiais se relacionavam com os demais moradores.

O que importa é que não tem mais tiroteio [...]. antes, o que acontecia era que [a polícia] chegava de qualquer jeito, atirando sem querer saber quem estava no caminho, e depois que morria [alguém], era só dizer que era bandido... o pior é que eles não estavam nem aí mesmo, se tivesse no caminho, o problema era seu. (Grifo meu).

Mais adiante, ela afirma:

Eu fui, sim, nas primeiras reuniões com a polícia. E o que eu gostei foi do que o comandante deles disse [...] que a preocupação era com a gente, com a nossa segurança, que eles estão tendo a gente como preocupação. Que o trabalho deles ia ser o de proteger o morador de favela. É isso que eles fazem lá embaixo todos os dias. Mas aqui, na favela, isso é novo.

Até o presente momento, apresentei algumas narrativas locais sobre o GPAE. Para completar o quadro, a partir de agora, trato de alguns procedimentos adotados pelo policiamento e que, segundo meus interlocutores, constrangeram o movimento e sinalizaram que estava em curso uma mudança na forma como os policiais agiam nas favelas.

\section{O controle territorial}

O Grupamento foi criado com a proposta de diminuir a sensação de medo e as situações de risco pessoal dos moradores das favelas. Assim, adotaria medidas para impedir que o movimento controlasse, por intermédio da intimidação exercida pela exposição e uso de armas de fogo, os espaços físicos e o trânsito de pessoas no interior destas áreas. De

4. A marcação em itálico indica que se trata de uma categoria ou fala nativa, e será usada somente na primeira aparição do termo que indica essa categoria ou fala. A partir da segunda aparição, o grifo não será mais necessário.

5. Como ficará evidente no decorrer do artigo, pessoa de bem e movimento são categorias locais amplamente difundidas e que costumam ser acionadas quando se trata de comparar pessoas e opções dentro das favelas. Envolvem noções de dignidade e moralidade. Enquanto movimento diz respeito ao crime organizado local, pessoa de bem pode se referir a todos que não aderiram ao crime. 
início seriam instalados postos de policiamento que contariam com a presença ininterrupta de policiais encarregados de realizar rondas preventivas em diversos momentos do dia. No Pavão-Pavãozinho e no Cantagalo, dois dos quatro postos de policiamento foram montados onde, anteriormente, funcionavam as bocas de fumo. A ocupação destes locais pelo PPC carregava um forte conteúdo emblemático. Naquele momento, o Grupamento destituía o tráfico do poder de apropriar-se de determinados espaços públicos com o objetivo de manter a dinâmica da venda de drogas. Isso sinalizava que, a partir dali, o movimento não poderia mais atuar nas favelas da forma como estava habituado.

Tal como apontado nas diretrizes do Grupamento, a repressão à venda de drogas ocupava um lugar secundário dentro de suas preocupações. Isso fica evidente quando se presta atenção à seguinte passagem: "repressão qualificada do tráfico e do uso de drogas na hipótese de flagrante delito”. Na prática, isso significava que o movimento poderia manter a venda de drogas desde que fosse realizada de forma discreta e sem ameaça à segurança dos demais habitantes das favelas.

Eles chegaram e dominaram. Então quem manda agora é essa polícia aí, e todo mundo teve que se ajeitar para não ter confusão. Do jeito que está agora não tem como a rapaziada dominar da forma que fazia [...]. Continuam por aí, mas pelo menos não tem mais morte nem outras coisas. (Augusto, Pavão-Pavãozinho).

\section{O constrangimento do porte de armas}

Diferente da postura sobre a venda de drogas, o uso e/ou a exibição de armamento pelo movimento estavam entre as preocupações centrais do GPAE. E a denúncia ou a constatação da presença de pessoas suspeitas nesse sentido acarretariam medidas repressivas prejudiciais à comercialização de drogas, além da prisão daqueles que fossem pegos portando armas. A partir de então, os traficantes tiveram que realizar suas operações e se relacionar com os demais moradores sem a utilização explícita da arma de fogo, o que produziu uma repercussão positiva:

Só destes meninos não estarem mais andando armados por aí, pra mim, já está muito melhor. A arma te assusta, você sabe. Te deixa insegura, apavorada. Sem essa coisa, eles são apenas meninos. Eles não são ruins...
Mas, com a arma na mão, é muito perigoso porque a gente não pode fazer muita coisa. (Conceição, moradora do Pavão-Pavãozinho).

\section{O fim das incursões}

Como a proposta do GPAE era atuar de forma preventiva e permanente, fazendo-se presente 24 horas nas localidades atendidas, foram suspensas nesses locais as chamadas batidas - incursões policiais destinadas à apreensão de drogas e de armas e ao cumprimento de mandados judiciais para a prisão de evolvidos com o tráfico. Para os moradores, as incursões eram sinônimo de tiroteios e arbitrariedade policial. Elas geravam apreensão e medo, uma vez que potencializavam riscos à vida. Enfim, com a presença permanente do Grupamento, percebeu-se que os tiroteios deixaram de ocorrer.

\section{A escuta}

O GPAE trazia a promessa de uma nova forma de interação com os moradores por meio da adoção de procedimentos que indicassem o respeito a eles e o interesse por sua segurança. Um desses procedimentos seria a disposição para a escuta dos moradores. Do ponto de vista do GPAE, isto significava a consideração da opinião dos residentes em duas situações: nas tomadas de decisões sobre melhores estratégias de atuação para a diminuição dos problemas; e na tomada de providências diante de eventuais denúncias sobre violência arbitrária ou ações criminosas praticadas por policiais. $O$ incentivo à participação na tomada de decisão guiava-se pelo já referido princípio da coprodução de segurança, um dos principais postulados teóricos do policiamento comunitário.

$\mathrm{O}$ que percebi durante o campo foi que os procedimentos adotados pelo comando do Grupamento diante de denúncias de malfeitos cometidos por policiais eram mais significativos, para meus interlocutores, do que a realização de reuniões com o objetivo de abrir espaço para que opinassem sobre a melhor estratégia a ser adotada pelo Grupamento. Ou seja, a escuta praticada pelos oficiais do Grupamento e significada como positiva pelos moradores, como uma demonstração de que suas falas eram levadas a sério, era aquela que resultava em punições aos policiais acusados de agir arbitrariamente e de cometer irregularidades ou crimes. ${ }^{6}$ Com essas punições, o comando do GPAE procurava demonstrar que sua disposição à escuta, seu incentivo à colaboração dos moradores

6. Segundo o comandante do Grupamento, em um ano, parte significativa do efetivo que compunha o policiamento nas favelas teve que ser renovada como resultado da comprovação de denúncias feitas pelos moradores (Blanco, 2003). 
na tentativa de correção de rumos, não era, por assim dizer, jogo de cena. As denúncias eram investigadas e, havendo indícios de comprovação, os responsáveis recebiam punição.

\section{Ao encontro das demandas dos moradores}

Como foi visto até aqui, a melhora momentânea no cotidiano das duas favelas observadas era atribuída à atuação do GPAE. Mas melhora em quê? Quais eram as práticas policiais que geravam insatisfação entre os moradores e o que isso revela sobre os parâmetros que, no momento da pesquisa, pautavam o olhar deles sobre a polícia e seus agentes? Grosso modo, as queixas mais comuns contra os policiais eram as seguintes: práticas abusivas, com uso excessivo e ilegal da força, execuções, existência de acordos corruptos que permitiam ao movimento controlar a ocupação dos espaços e a sociabilidade nas favelas, além de procedimentos que colocavam em risco a vida daqueles que lá moravam. No entendimento local, a existência desses acordos representava um problema porque, através deles, o movimento podia manter o controle coercitivo sobre os demais moradores sem se preocupar com uma possível intervenção policial. A propósito, para os moradores das duas favelas, a corrupção constituía uma prática corrente entre os policiais. Sua presença não era associada com a garantia da integridade física ou da segurança, nem com a repressão à comercialização de drogas ilícitas, nem com a busca dos indivíduos que cometiam delitos. Era vista como a parte do acordo que possibilitava o controle do local deixando as pessoas de bem à mercê dos humores do movimento.

No que se refere à maneira como as operações policiais eram conduzidas dentro das favelas, reclamava-se das incursões e seus desdobramentos, que eram, certamente, um dos principais alvos de queixas contra a polícia. Também apontavam que os policiais se comportavam de maneira diferente nas favelas e no asfalto.

Mas quando é na Atlântica ou na Vieira Souto, aí é diferente. Não se atira porque não pode botar em risco um doutor ou a madame. Só se atira quando não tem jeito, não é?! Aí a polícia negocia, chama advogado, promete que não vai matar. Só pra não colocar em risco a vida. Por que com o morador do morro tem que ser diferente? Nós somos humanos também. A maioria aqui é gente que trabalha, que acorda cedo, que paga as contas e quer ser respeitado. Eu também quero que a polícia não ponha minha vida em risco. (Débora, Cantagalo, grifo meu).
Quanto à violência abusiva cometida por policiais, pode-se classificá-la em dois tipos: os abusos de autoridade com a utilização de violência excessiva e as mortes - sobretudo mortes com suspeita de execução. O entendimento nas favelas era de que qualquer pessoa, sem distinção, poderia tornar-se alvo de violência policial, fosse homem ou mulher, criança ou adulto, pertencesse ao movimento ou não. E era justamente este caráter indiscriminado da violência policial que gerava maior desconforto.

Pra polícia só tem bandido aqui. Na verdade eles sabem que não é assim, que tem muita gente trabalhadora, que não faz nada errado, que não se mete com o crime. Mas eles não se importam, fingem que é tudo bandido. Não tem um que morra que não aparece no jornal dizendo que era envolvido. Então é todo mundo. (Ruth, Pavão-Pavãozinho).

A fala de Ruth é especialmente interessante por destacar uma distinção central na concepção de mundo dos meus interlocutores nas duas favelas. Refiro-me à diferenciação, carregada de conteúdo moral, e por isso valorativa, entre quem pertence ao movimento e quem não está associado a ele. Essa distinção é sociologicamente relevante porque era nela que meus interlocutores fundamentavam suas expectativas por tratamento diferenciado. Por exemplo, mesmo que a violência abusiva ou o assassinato cometidos por policiais fossem reprováveis independente da adesão ou não do indivíduo ao crime organizado, a repercussão negativa, o sentimento de ofensa, mostrava-se mais intenso quando as pessoas vitimadas não pertenciam ao movimento. E mais: essas situações violentas demonstrariam, de forma inequívoca, a incapacidade ou a recusa dos policiais em reconhecer a diferenciação entre as pessoas de bem e os envolvidos com o tráfico.

Tal como entendo, a maneira como meus interlocutores falavam da presença do GPAE e reagiam a ela, enfim, suas narrativas sobre os procedimentos que os incomodavam, se aproxima daquilo que Honneth (1996), Taylor (1994) e Cardoso de Oliveira (2002) tratam como "demandas por reconhecimento moral". Afinal, tanto as narrativas positivas sobre o GPAE quanto as críticas à polícia tinham como referência uma determinada noção de dignidade construída e compartilhada entre meus interlocutores. A noção de respeito, repetidamente acionada por eles, ocupava um lugar central no discurso local. Por meio dela, essas pessoas significavam suas experiências com a polícia e com o tráfico. Defendo que, sem a devida atenção a esta categoria e à teia de significados em que ela se insere, parece improvável que consigamos enxergar com clareza os motivos para uma boa avaliação do Grupamento. Com isto estou assumindo que o cerne da questão não está no impacto causa- 
do pelos procedimentos adotados pelo GPAE, se eles modificaram ou não o cotidiano local, mas sim na forma como os moradores do Cantagalo e do Pavão-Pavãozinho significaram estes procedimentos.

Como fica evidente nas falas de Ruth e Débora, as reclamações contra a polícia nas duas favelas eram elaboradas com o entendimento de que os agentes não respeitavam os moradores. As práticas desrespeitosas se materializavam no uso arbitrário e ilegal da força, letal ou não, e nos descasos e omissões expressos por práticas corruptas ou por incursões nas favelas. Todas estas práticas, com maior ou menor amplitude, alimentavam uma percepção de aviltamento responsável pela avaliação negativa que os moradores de ambas as favelas faziam da polícia. A corrupção policial era vista como um problema porque os deixava vulneráveis e à mercê do movimento, situação experimentada como um descaso com sua integridade física e moral. De modo semelhante, também era vista como descaso a maneira como as operações policiais eram conduzidas nessas favelas, provocando tiroteios e colocando a vida dos moradores em risco. Fosse caracterizado pela omissão, fosse pela negligência, o descaso era vivenciado como uma demonstração de desrespeito.

As agressões físicas perpetradas por policiais contra os indivíduos que se autodenominavam pessoas de bem, trabalhadoras, cumpridoras de suas obrigações, também eram consideradas como atos deliberadamente praticados com o intuito de infligir-lhes humilhação. O tom adotado diante de episódios desta natureza era o da indignação coletiva gerada pela incapacidade ou desinteresse dos policiais em reconhecer a condição moral desses indivíduos.

A percepção acerca da polícia estava associada com o entendimento que os moradores tinham sobre procedimentos adotados pelos agentes: se eram respeitosos ou não, se reconheciam ou não a condição moral das pessoas. Quando consideravam ter sofrido desrespeito, as narrativas apresentavam uma estrutura semelhante: havia o apontamento do ato que causara a queixa propriamente dita; a indicação de que este ato era vivenciado como um desrespeito; e, por fim, a explicitação da demanda e do desejo de mudança desta situação. As falas de Ruth e Débora, assim como outras tantas, ainda que não se construíssem necessariamente nesta mesma ordem, são um bom exemplo disso. Ambas se queixavam da forma como os agentes levavam a cabo suas operações nas favelas e, consequentemente, do tratamento dispensado aos moradores, identificando estas práticas como desrespeitosas para então afirmar que gostariam de ser tratadas de forma diferente.

Como é possível observar pelo apresentado das falas e reações, o GPAE representou, ao menos por algum tempo, uma experiência diferente no cotidia- no das duas favelas. Durante um período determinado, a presença da polícia não significou, para os moradores locais, uma experiência automaticamente negativa. Naquele momento, eles não consideraram as ações de seus agentes como expressão de desconsideração e desrespeito para com as pessoas de bem. A maneira como o policiamento interferia no controle territorial das favelas pelo tráfico era experimentada como algo positivo. Como disse Augusto, os policiais do GPAE "chegaram e dominaram", e com isso o movimento teve que modificar a forma como procedia nas favelas. A presença dos policiais do GPAE fez com que os episódios de violência, abusos e desrespeito cometidos por traficantes se tornassem menos frequentes, conforme observado nas falas de Ruth e suas filhas. A repressão à exposição de armas de fogo também era vista como uma demonstração de cuidado com a segurança daqueles que não pertenciam ao movimento, como dito por Conceição. O mesmo se pode dizer com respeito ao fim dos tiroteios, à modificação do tratamento dispensado por policiais aos moradores em sua relação direta com eles e à postura do comando do GPAE quando da constatação de desvio de conduta de seus agentes. Esses procedimentos foram interpretados como demonstrações de preocupação com o bem-estar e a segurança dessas pessoas, um indício de que agora elas estavam sendo respeitadas.

Um aspecto importante para meu argumento neste artigo e presente na cosmovisão local é a existência de uma relação indissociável entre a noção de respeito apresentada pelos moradores das duas favelas e suas concepções de direitos e justiça. Todavia, para perceber isso, é necessário, em primeiro lugar, observar que os recorrentes acionamentos de categorias como pessoas de bem e trabalhadores aparecem como forma de explicitar a insatisfação com os tratamentos considerados inadequados e/ou ofensivos.

A adesão discursiva a determinada ética do trabalho habilita os indivíduos a ter seus direitos respeitados e distingue aqueles que aderiram ao movimento dos que são pessoas de bem. Para meus interlocutores, o problema estava justamente no fato de que, em suas práticas, os policiais não reconheciam esta distinção e, por conseguinte, não davam tratamento diferenciado aos trabalhadores. E a maneira como os policiais procediam indicava, dentro dessa perspectiva, que a única diferença considerada por eles era a que opunha os moradores das favelas aos moradores do asfalto, quando deveria operar o reconhecimento da oposição entre traficantes/bandidos, de um lado, e trabalhadores/pessoas de bem, de outro. Afirmações como a maioria aqui é gente que trabalha revelam uma moralidade segundo a qual aqueles que trabalhavam e não aderiram ao crime deveriam, independente de sua condição socioeconômica, ter seus direitos ga- 
rantidos. Isso implica dizer que as insatisfações com os comportamentos que os moradores consideravam desrespeitosos e as demandas por respeito não conservavam relação com a observância ou não dos preceitos constitucionais, que defendem o alcance universal dos direitos de cidadania.

O respeito de que tanto falavam os residentes nas duas favelas não corresponde ao acatamento à norma; trata-se do respeito conferido à pessoa (Cardoso, 2013). Segundo eles, o indivíduo, dependendo das suas escolhas, merece ter sua dignidade reconhecida por meio de um tratamento adequado, muito próximo daquele que Cardoso de Oliveira (2011b) classificou de "substância moral das pessoas dignas". O autor sugere que a noção de igualdade como medida consagrada dentro do modelo de análise tradicional da cidadania não foi capaz de produzir respostas adequadas diante das demandas contemporâneas por respeito a direitos. Segundo ele, os novos conflitos que emergem na esfera pública têm como característica a indignação diante da percepção de que a condição moral de indivíduos ou grupos não é reconhecida, já que não os torna alvo de um tratamento que considere sua dignidade.

Assim, não é a ausência do compartilhamento de uma percepção mútua de igualdade a fonte das demandas hodiernas (Cardoso de Oliveira, 2011a). A análise das falas apresentadas aqui permite considerar que se trata de demandas por reconhecimento da dignidade, materializadas na fala dos meus interlocutores pela expectativa de tratamento respeitoso. Os procedimentos policiais apontados como problemáticos são os vivenciados como desconsideração à condição moral das pessoas de bem e dos trabalhadores. Em contrapartida, a forma como o GPAE atuava nas favelas despertou nos moradores o sentimento de que estavam recebendo tratamento digno. Em outras palavras, o Grupamento foi capaz de fazer com que os moradores se sentissem respeitados.

\section{A UPP e os moradores das favelas em análise}

Em 23 de dezembro de 2009, mais uma vez, as favelas do Pavão-Pavãozinho e do Cantagalo tornaram-se palco de uma iniciativa da Secretaria Estadual de Segurança Pública do Rio de Janeiro: a UPP. Desde então os moradores contaram com a permanência ininterrupta de policiais nas localidades. A sede local da unidade encontra-se ao lado do Espaço Criança Esperança, no fim da Estrada do Cantagalo, dentro da favela que recebe o mesmo nome. A UPP, também alegadamente inspirada nos princípios do policiamento comunitário e/ou de proximidade, foi criada para atuar especificamente em favelas. Tem dois objetivos explícitos: a desarticulação do domínio territorial de bandos organizados para a comercialização de drogas ilícitas; a garantia do exercício dos direitos civis básicos dos habituais moradores destas áreas não envolvidos nas atividades do tráfico. A UPP possui sede e um efetivo próprio que conta com a presença de um oficial comandante e dos demais oficiais, dos sargentos e praças, que reproduzem a estrutura hierárquica institucional da polícia militar do estado do Rio de Janeiro. Cada uma destas unidades vincula-se ao Batalhão da Polícia Militar mais próximo de sua área de implantação e atuação, e todas elas estão submetidas à supervisão e orientação da Coordenadoria da Polícia Pacificadora (CPP). A Coordenadoria tem sede em Bonsucesso, bairro pobre da zona norte do município do Rio de Janeiro. A sede se localiza em frente ao Complexo do Alemão, conjunto de favelas nacionalmente conhecido em virtude da atuação dos bandos armados que usam a região como base das suas operações. Segundo informação veiculada pelo governo do estado no sítio da internet institucional, dedicado exclusivamente à UPP, a Coordenadoria foi criada no dia 6 de janeiro do ano de 2011 com o objetivo de "coordenar a implantação e as ações operacionais das Unidades de Polícia Pacificadora" e "avaliar e monitorar" o funcionamento de cada uma delas. ${ }^{7}$

A primeira UPP foi inaugurada no dia 12 de dezembro de 2008, na favela Santa Marta, situada no Bairro de Botafogo, zona sul da cidade do Rio de Janeiro. Um relatório produzido por Cano e Borges (2012) aponta que dezenove UPP foram instaladas desde essa data inaugural até janeiro de 2012. Como demonstraram os autores, a estrutura normativa que determina as atividades das UPP é exígua. São três decretos e uma nota emitida pelo comandante-geral da polícia militar do Rio de Janeiro. Os aspectos jurídicos associados à criação da UPP não são essenciais para as reflexões que proponho neste artigo, portanto seguirei sem apresentá-los.

Diferente do que ocorrera com o GPAE, não tive oportunidade de acompanhar o período inicial das atividades da UPP nas duas favelas. Meu retorno ao Pavão-Pavãozinho e Cantagalo aconteceu em 2013 e estendeu-se até meados de 2014, aproximadamente cinco anos após minha última incursão de campo para o doutorado. A partir de 2013, estive interessado tanto no impacto provocado pela presença da UPP no cotidiano das duas localidades, quanto na opinião dos seus moradores sobre o fato. Sendo assim, nas entre- 
vistas e conversas com meus interlocutores, procurei resgatar suas lembranças, sensações e opiniões sobre o período de implantação dessa instituição nas favelas e confrontá-las com seus julgamentos hodiernos. Esse período é lembrado, sobretudo, por conta de dois fatores: a presença massiva de efetivo policial nessas comunidades e o efeito imediato dessa presença no cotidiano local, como indicam as falas de alguns dos meus interlocutores.

Lembro que foi em 2010, não, 2009, acho que no final de 2009. Eu lembro que eles... a gente já sabia que ia acontecer. Eles chegaram, eu estava no trabalho, não estava no dia aqui, só lembro que, quando eu estava chegando do trabalho, tinha muita polícia e tudo mais, e os helicópteros. Mas eu não estava aqui no dia, em si, mas depois foi melhorando. Já tinha muita polícia e tudo mais, e a gente realmente deixou de ver, realmente, o tráfico com armas com tanta frequência. (Entrevista concedida em 2013).

Dependendo da pessoa, a percepção sobre a reação do tráfico sofre variação. Enquanto uns afirmavam que os traficantes continuaram nas favelas, mas sem realizar suas operações costumeiras, outros entendiam que, nesse primeiro momento, ocorreu uma fuga em massa.

Acho que no primeiro momento eles fugiram mesmo. Bom, essa é a impressão que eu tenho. Não sei precisamente, mas a impressão que eu tenho é que eles fugiram mesmo e não ficaram aqui durante um bom tempo, até porque tinha muito mais policiais aqui, o Bope e tudo mais, então..... (Entrevista concedida em 2013).

Outro interlocutor, ao relembrar esse primeiro momento, sugeriu que, de maneira geral, seus vizinhos simpatizavam com o policiamento.

Então, pra mim, a impressão que eu tenho é que os moradores gostaram, assim, acho que a primeira impressão dos moradores que não têm envolvimento com o tráfico foi que eles gostaram, né? que melhorou, muito, a qualidade de vida pro que era e pro que é agora, é muito diferente. (Entrevista concedida em 2013).

A maioria das falas compartilhadas comigo sobre o impacto inicial provocado pela presença da UPP se assemelhava ao observado acerca do GPAE. A ausência das incursões e a diminuição dos tiroteios com a desestabilização do domínio territorial do bando local que ditava as regras de socialidade nas duas favelas foram consequências recorrentemente lembradas por meus interlocutores. Eram sempre expressas como uma espécie de impacto que beneficiava as pessoas de bem, já que elas não se viam mais submetidas àquelas experiências negativas na mesma proporção que antes da chegada da UPP.

Todavia, nos últimos meses do ano de 2013 e na primeira metade do ano de 2014, quando estive nas favelas realizando pesquisa de campo, presenciei o aumento da atuação do tráfico no local e seus naturais resultados: o retorno ao controle de espaços públicos pelos traficantes dentro das favelas; e a volta de comportamentos que provocavam a intimidação dos demais moradores, como assassinatos e troca de tiros com policiais.

Os jornais também registraram o aumento da tensão no Cantagalo e no Pavão-Pavãozinho. Na segunda metade do mês de outubro de 2013, quando ainda estava realizando minha pesquisa etnográfica, houve um intenso tiroteio entre policiais e traficantes no Pavão-Pavãozinho. Segundo meus interlocutores, este havia sido o primeiro episódio de grande magnitude desde a implantação da UPP. Em janeiro de 2014, ocorreu outro tiroteio da mesma natureza e na mesma comunidade. Em março, policiais foram encurralados por traficantes dentro da favela. Antes destes episódios, ainda durante 2013, escutava dos meus interlocutores que, conforme vinha avisando o movimento, até o fim daquele ano, os policiais seriam expulsos da favela, e todos que tivessem colaborado com eles seriam executados. Em maio de 2014, quando retornei à favela, a UPP não havia sido expulsa, tal como prometido pelo movimento, mas o comportamento dos traficantes estava sensivelmente mais agressivo.

Como exemplo, há o caso da família de mulheres residentes no Pavão-Pavãozinho que estavam sofrendo ameaças de traficantes. Segundo elas, estes pretendiam expulsá-las para tomar as casas de sua propriedade dentro das favelas. O receio generalizado dos moradores de falar sobre a UPP também era um forte indicativo do retorno do poder do tráfico às localidades. Destaque-se ainda que, por três vezes, fui impedido de entrar nas favelas em razão de operações policiais que desencadearam confrontos com os adeptos do bando armado que controla a venda de drogas. Além disso, na última semana de minha pesquisa de campo, alguns moradores pediram-me, em tom de desespero, para que não retornasse ao Pavão-Pavãozinho, porque estavam com medo da reação do tráfico.

Por tudo isso, aqueles que se prontificavam a falar comigo sobre a UPP, em sua maioria, colocavam a condição da não gravação da entrevista e/ou de conversas. E nos casos em que pude gravá-las, evidenciavam-se a tensão dos meus interlocutores e seu medo de estarem sendo ouvidos pelos vizinhos. Tudo isso fez com que parte dos moradores que me diziam apoiar a presença da UPP passasse a se mostrar 
descrente com a permanência do projeto ao longo do tempo. Os ganhos que os moradores alegavam ter sido conquistados com a chegada da UPP estavam, segundo sua opinião, se perdendo. Essa queda gerava, inclusive, uma percepção de que a população estava sofrendo desconsideração por parte do poder público.

\section{Considerações finais}

Há muitas semelhanças entre os procedimentos adotados pelo GPAE e os adotados pela UPP nas favelas do Cantagalo e do Pavão-Pavãozinho. Tanto o GPAE quanto a UPP se caracterizavam por operar dentro da lógica do domínio territorial. Em determinado nível, a intenção era demonstrar, não apenas para os traficantes que dominavam a venda de droga nas localidades, como também para os demais moradores, que, a partir da chegada dos operativos da polícia militar, estas áreas passariam a estar sob o domínio dos agentes policiais. Dali em diante seriam eles, e não os traficantes, que ditariam as regras de socialidade e de ocupação de espaço dentro das favelas. Ao menos por determinado período, tanto os policiais do GPAE quanto os da UPP tornaram-se os "donos do morro" (Cano; Borges, 2012).

Todavia, há diferenças na forma como cada um destes projetos exerceu tal ocupação. A UPP contou com apoio financeiro para construir um prédio na favela do Cantagalo e usá-lo como sede para seus agentes. O GPAE não tinha a mesma estrutura física; operava em postos improvisados. Outra diferença significativa de atuação era a raridade com que se viam os policiais da UPP circulando dentro das favelas. Normalmente, esses agentes ocupam o acesso às favelas e a sede, mas, nas localidades estudadas, era raro vê-los nos acessos e ruelas. Ficavam em seus postos e de lá quase nunca saíam. No caso do GPAE, durante algum tempo, os policiais realizavam rondas duas ou três vezes por dia, circulando pelas favelas. A adoção desse procedimento acabava dificultando a consolidação da ocupação dos espaços pelo tráfico.

Não por acaso, no período em que acompanhei a atuação da UPP, podiam-se identificar, sem grandes esforços, espaços pertencentes ao tráfico, onde se encontravam os traficantes reunidos portando e expondo suas armas de fogo. Todavia, tanto a UPP quanto o GPAE alegavam priorizar a repressão à exposição de armamento de fogo pelo movimento. O constrangimento do porte de arma fazia parte das estratégias para enfraquecer o domínio do bando, numa tentativa de impedir que seus adeptos exercessem o controle das localidades com a intimidação provocada pela exposição de armas. A atenção dada à questão do porte de armas também visava cumprir o objetivo de combater os índices de mortes dentro das favelas.
Todavia, a longo prazo, nem a UPP nem o GPAE se mostraram capazes de constranger a presença de armas nas favelas e seu porte pelos traficantes. As vantagens da ocupação permanente dessas localidades pelos dois dispositivos restringiram-se, no âmbito das armas, à diminuição dos confrontos com troca de tiros entre policiais e traficantes. Este, aliás, foi um dos principais alvos de elogio dos moradores. Contudo, após um período inicial marcado pela desarticulação do bando armado, ambas as instituições presenciaram o progressivo fortalecimento desse bando. Sem dizer do aumento da tensão entre policiais e traficantes e da multiplicação dos confrontos entre os grupos das duas favelas.

Uma diferença significativa entre o GPAE e a UPP é que o primeiro buscou criar condições para o estabelecimento do diálogo com os moradores das duas favelas. Reuniões eram marcadas e a escuta era exercitada pelo comando do GPAE. Isso se devia à inspiração que conduziu a criação do projeto. Classificando-se como um projeto de policiamento comunitário, o GPAE, por meio de seus agentes, procurava criar um tipo de relação que proporcionasse aquilo que em segurança pública é chamado de coprodução de segurança. Por sua vez, a UPP, apesar de inicialmente ser classificada por seus idealizadores de policiamento comunitário, posteriormente modificou esta nomenclatura para policiamento de proximidade. Isto explica por que essa instituição não dialoga com os moradores das favelas, já que, nesse tipo de policiamento, não há uma proposta de diálogo horizontal com a comunidade.

As comparações no quesito percepção dos moradores sobre os projetos também revelam uma significativa similaridade entre UPP e GPAE. Apesar da desconfiança para com os policiais e do medo de retaliações advindas do tráfico, ainda que a presença deste já fosse discreta, os dois projetos tiveram, de maneira geral, uma recepção positiva entre os moradores não envolvidos com o bando armado. Isto porque há resistência contra a atuação do tráfico nas favelas. Eles o temem, são vítimas de suas arbitrariedades, sofrem diversas modalidades de abusos físicos e insultos morais. Sofrem ameaças e intimidações sem que, na maioria das vezes, tenham a quem recorrer para prestar queixa, alguém que possa mediar uma solução. Concretamente, a ideia do bom bandido que protege e garante a ordem nas favelas não se materializa atualmente nas ações reais dos agentes do tráfico. Por isso, a presença e a atuação de projetos da natureza dos discutidos neste artigo são alvos de inicial receptividade positiva. Pelo menos enquanto conseguem mostrar-se como iniciativas que visam garantir a integridade física e moral dos moradores de favelas, enquanto seus agentes demonstram preocupação com a segurança, o bem-estar e a vida dos que aí habitam. 
Todavia, quando estas iniciativas não se mostram, ao longo do tempo, capazes de desarticular de maneira definitiva o tráfico, ou quando os policiais passam a revelar procedimentos que se assemelham aos adotados pelos traficantes, começam a surgir descontentamentos com os projetos nas localidades em que eles atuam. Sem falar de questões da ordem das percepções sobre consideração ou desconsideração da dignidade e que também geram insatisfação nos moradores. Trata-se de questões associadas a concepções locais de justiça e direitos e que se aproximam daquilo que alguns autores consultados aqui chamam de demandas por reconhecimento.

\title{
Referências
}

ALBERNAZ, Elizabete Ribeiro; CARUSO, Haydée Glória Cruz; MORAES, Luciane Patrício Braga de. Tensões e desafios de um policiamento comunitário em favelas do Rio de Janeiro: o caso do Grupamento de Policiamento em Áreas Especiais. São Paulo em Perspectiva, n. 21, p. 39-52, 2006.

BLANCO, Antônio. Sobre a experiência prática. Comunicações do ISER, ano 22, n. 58, p. 101-109, 2003.

CANO, Inácio; BORGES, Dorian (Org.). Os donos do morro: uma análise exploratória do impacto das Unidades de Polícia Pacificadora (UPPs) no Rio de Janeiro. 1. ed. São Paulo: Fundo Brasileiro de Segurança Pública, 2012. CARDOSO DE OLIVEIRA, Luís Roberto. Direito legal e insulto moral: dilemas de cidadania no Brasil, Quebec e EUA. Rio de Janeiro: Relume-Dumará, 2002.

CARDOSO DE OLIVEIRA, Luís Roberto. A dimensão simbólica dos direitos e a análise dos conflitos. Revista de Antropologia, São Paulo, n. 53, p. 451-473, 2011a.

CARDOSO DE OLIVEIRA, Luís Roberto. Concepções de igualdade e cidadania. Contemporânea: Revista de Sociologia da UFSCar, v. 1, p. 35-48, 2011b.

CARDOSO DE OLIVEIRA, Luís Roberto. Equality, dignity and fairness: Brazilian citizenship in comparative perspective. Critique of Anthropology, v. 33, n. 2, p. 131-145, 2013.

CARDOSO, Marcus. A dimensão simbólica dos conflitos: moradores de favela e polícia. Anuário Antropológico, n. 2012-1, p. 167-190, 2013.

HONNETH, Axel. The struggle for recognition, the moral grammar of social conflicts. Cambridge: The MIT Press, 1996.
MOORE, Michael. Policiamento comunitário e policiamento para solução de problemas. In: TONRY, Michael; MORRIS, Norval (Org.). Policiamento moderno. São Paulo: Edusp, 2002. p. 115-175.

NÚCLEO DE ESTUDOS DA VIOLÊNCIA DA UNIVERSIDADE DE SÃO PAULO. Manual de policiamento comunitário: polícia e comunidade na construção da segurança. São Paulo, 2009. Disponível em: $<$ http://www.dhnet.org.br/dados/manuais/dh/manual_ policiamento_comunitario.pdf $>$.

PERLMAN, Janice. O mito da marginalidade: favelas e política no Rio de Janeiro. Rio de Janeiro: Paz e Terra, 1977.

ROSENBAUM, David. A mudança no papel da polícia: avaliando a transição para policiamento comunitário. In: BRODEUR, Jean-Paul (Org.). Como reconhecer um bom policiamento comunitário. São Paulo: Edusp, 2002. p. 27-55. SKOLNICK, Jerome; BAYLEY, David. Policiamento comunitário. São Paulo: Edusp, 2002.

SOARES, Luiz Eduardo. Segurança pública: presente e futuro. Estudos Avançados, n. 20, p. 91-106, 1996.

TAYLOR, Charles. The politics of recognition. In: GUTMANN, Amy (Org.). Multiculturalism and the politics of recognition. New Jersey: Princeton University Press, 1994. p. 25-74.

VALLADARES, Licia do Prado. A invenção da favela. Rio de Janeiro: FGV, 2005.

ZALUAR, Alba. A máquina e a revolta. São Paulo: Brasiliense, 1985.

\section{From the GPAE to the UPP. A proposal to interpret the perceptions of favela residents about community policing and proximity projects}

\begin{abstract}
In this article I intend to explore the factors involved in the evaluation of the Peacekeeping Police Unit (UPP - in Portuguese) and Special Areas Policing Grouping (GPAE - in Portuguese) by the residents of two favelas located in Rio de Janeiro. In order to carry out this proposition it is necessary to pay careful attention to what is said by the interlocutors. In thus proceeding it is possible to identify in their discourse recurrences which refer to structures of meanings by means of which they interpret their experiences. In
\end{abstract}


this paper I sustain that, in order to adequately understand the perception of the residents of the favelas about the UPP and GPAE, one must observe the importance they attach to practices they designate as respectful and disrespectful, categories that permeate their interpretation of police performance. I hence seek to explore the analytical potential of approaching the native categories respect and disrespect and the analytical categories consideration and moral insult.

Keywords: Community policing, favelas, recognition, moral insult, respect.

\section{GPAE de la UPP: una propuesta de interpretación de las percepciones de los habitantes de barrios marginales sobre los proyectos de vigilancia comunitaria y de proximidad}

\section{Resumen}

Este artículo explora los factores que intervienen en el proceso de evaluación de la Unidad de Policía Pacificadora (UPP) y de la Agrupación de la Policía en zonas especiales (GPAE) por los vecinos de dos barrios pobres (dos favelas cariocas). Un trabajo de esta naturaleza sólo puede ser realizado cuando dedicamos cuidadosa atención a lo que dicen nuestros interlocutores. Proceder de esta manera nos permite identificar en sus testimonios posibles recurrencias que remiten a las estructuras de significado con las que interpretan sus experiencias. Una comprensión adecuada de la percepción de los habitantes de las favelas observadas acerca del GPAE y de la UPP sólo es posible si nos fijamos en la importancia que estas personas atribuyen a las prácticas que ellos llaman "respetuosas" o "irrespetuosas", al apreciar las acciones de los que actúan en esas favelas. Con esa visión, exploramos el potencial analítico de las aproximaciones entre las categorías respeto y falta de respeto y las categorías analísticas consideración e insulto moral.

Palabras clave: Policía comunitaria, favelas, reconocimiento, insulto moral, respeto.

Data de recebimento do artigo: 05/2016

Data de aprovação do artigo: 11/2016 